\title{
MODULATION OF THE ANTIBIOTIC SUSCEPTIBILITY PROFILES OF SOME MICROBIAL STRAINS ISOLATED FROM WASTEWATER UNDER THE INFLUENCE OF THE ELECTROMAGNETIC FIELD
}

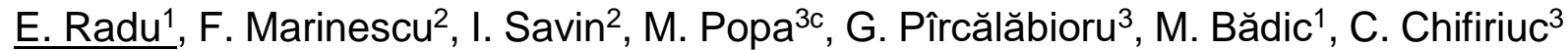

IINCDIE ICPE-CA, 313 Splaiul Unirii, Bucharest, Romania elena.radu@icpe-ca.ro ; mihai.badic@icpe-ca.ro

${ }^{2}$ National Institute for Research and Development in Environmental Protection INCDPM, Bucharest, Romania.

${ }^{3}$ Research Institute of the University of Bucharest - ICUB, University of Bucharest, 9195 Splaiul Independentei, Bucharest, Romania.

\begin{abstract}
The wastewater treatment plants are considered to be hotspots for antibiotic resistance selection, transfer and dissemination. Wastewater offers favorable conditions for the development of antibiotic resistant bacteria because it contains high amounts of organic matter, favoring the rapid multiplication of microbial cells and the development of biofilms in which microbial cells are in close proximity, the presence of pollutants (pesticides, heavy metals, antibiotics) acting as selective pressure agents for resistance.

The aim of this paper is to investigate how the antibiotics susceptibility profiles of some microbial strains isolated from wastewater are influenced by electromagnetic fields.

A number of 10 bacterial strains isolated from wastewater (E. coli, Salmonella $s p$., Enterobacter sp., Enterococcus sp., Citrobacter sp., Klebsiella sp.) were exposed to an electromagnetic field $\left(50 \mathrm{~Hz}\right.$ electric field at different voltages) for 24 hours, at $37^{\circ} \mathrm{C}$. Thereafter, the antibiotic susceptibility testing was performed for both treated and control strains, by disk diffusion method, according to CLSI 2016.

The obtained results proved that the electromagnetic field induced in some cases a decrease of the growth inhibition diameters such as penicillins, cephalosporins, aminoglycosides and vancomycin, while in other cases an increase of bacterial strains susceptibility to the tested antibiotics.

These preliminary results demonstrate that the electromagnetic filed in addition with other selective factors which are present in the wastewaters could modulate the environmental reservoir of antibiotic resistance and influence the frequency of the selection of resistant bacteria and the magnitude of the potential risk of dissemination into the environment and of contamination of animals and humans.
\end{abstract}

Keywords: antibiotic susceptibility, bacteria, electromagnetic field, wastewater.

\section{Introduction}

In recent years, due to the intensive use of antibiotics for humans health (domestic or clinical use), in veterinary purposes or in agriculture, the compounds are released constantly in the environment by anthropogenic sources such as wastewater treatment plants, considered to be hotspots for antibiotic resistance selection, transfer and dissemination in natural ecosystem (1-6). The wastewater treatment plant offers favorable conditions for the development of antibiotic resistant bacteria because it contains high amounts of organic matter, favoring the rapid multiplication of microbial cells and the development of biofilms in which microbial cells are in close proximity, the presence of pollutants (pesticides, heavy metals, antibiotics) acting as selective pressure agents for resistance (7-12). Presently, antibiotic resistance has become a 
global problem, being reported more and more clinical infections, diseases and deaths caused by resistant microorganisms $(8 ; 13-14)$. Beside the chemical pollution caused by the release of toxic substances in wastewater, the use of antibiotics induces the development of antibiotic resistant bacteria and antibiotic resistance genes which pose an increase risks to human and animals health (15).

The contamination of the natural environment with both antibiotic resistant bacteria and antibiotic resistance genes could have a negative impact on the structure and metabolism of bacterial populations (16-17). Therefore, it is necessary to identify their abundance and tolerance in polluted environments, such as the wastewater from wastewater treatment plants. The severity and persistence of antibiotic resistance genes in the natural environment represent an international priority problem (18-21). Investigation of the occurrence of antibiotics in wastewater has been conducted in several countries in Europe (22-25; 4). Boxali (2004) and Kummerer (2009) reported two important comprehensive studies regarding the ecotoxicity of antibiotics (26; 4). Different studies regarding the spread of antibiotic resistance bacteria and antibiotic resistance genes in wastewater were reported over time (27-32).

In contrast to the usual pollutant factors, which are well known (for example chemical or acoustic pollution), the electromagnetic pollution of the natural environment and its effects on the living matter are relatively little known. The electromagnetic fields have been demonstrated to influence the biological systems both in vivo and in vitro models. The biological effects depend on the intensity, frequency, the modulation type and shape of the electromagnetic field, but also the time of exposure also influences the results (33). The effects of electromagnetic waves below $1 \mathrm{kHz}$ on the living cells were studied for the first time in 1977 by Andrew A. Marino and Robert O. Becker (34).

A large number of bioprocesses can be improved by electromagnetic and electrochemical stimulation, under proper conditions of microbial cultivation (electrolyte bioreactors) (33). The bio electromagnetic stimulation of the microbial strains represents an important area with various applications in biotechnologies and bioenergy (35). Several studies were reported regarding the influence of electromagnetic field on both prokaryotic (bacteria) and eukaryotic (molds, yeasts, algae) microorganisms (33).

The aim of this paper is to investigate how the antibiotics susceptibility profiles of some microbial strains isolated from wastewater are influenced by electromagnetic fields.

\section{Materials and methods}

A number of 10 bacterial strains isolated from wastewater were investigated. The laboratory code, isolation sites and taxonomic affiliation are summarized in Table 1.

Table 1. Investigated bacterial strains

\begin{tabular}{|c|c|c|c|}
\hline No. & ID & Bacterial strains & Origin \\
\hline 1. & S18 & Salmonella arizonae & Sewage water \\
\hline 2. & P34 & Klebsiella sp. & Treated wastewater Bucharest \\
\hline 3. & S11 & Salmonella sp. & Sewage water \\
\hline 4. & N85 & $\begin{array}{c}\text { Enterobacter } \\
\text { agglomerans }\end{array}$ & Wastewater Fundeni Hospital \\
\hline 5. & N61 & Escherichia coli & Wastewater Fundeni Hospital \\
\hline
\end{tabular}




\begin{tabular}{|c|c|c|c|}
\hline 6. & N60 & Citrobacter farmeri & Wastewater Fundeni Hospital \\
\hline 7. & N67 & Klebsiella oxytoca & Wastewater Fundeni Hospital \\
\hline 8. & O19 & Enterobacter $s p$. & Domestic wastewater Bucharest \\
\hline 9. & P62 & Enterococcus $s p$. & Treated wastewater Bucharest \\
\hline 10. & R73 & Enterococcus $s p$. & Dambovita river water Bucharest \\
\hline
\end{tabular}

The bacterial strains were grown on Mueller-Hinton agar (MHA) and placed in an incubator for 24 hours at $35 \pm 2^{\circ} \mathrm{C}$, in an electrical installation, for obtaining a homogeneous electric field of $50 \mathrm{~Hz}$ electric field and different voltages (Table 2).

Table 2. Bacterial strains laboratory code and the type of the applied electric field

\begin{tabular}{|c|c|}
\hline Bacterial strains & Voltage \\
\hline N61-N67 & $217 \mathrm{~V}$ \\
\hline S11-S18 & $420 \mathrm{~V}$ \\
\hline P34-R73 & $665 \mathrm{~V}$ \\
\hline O19-P62 & $875 \mathrm{~V}$ \\
\hline N60 - N85 & $1120 \mathrm{~V}$ \\
\hline
\end{tabular}

The inoculum for testing the antibiotic susceptibility was represented by a direct colony suspension for each strain, equivalent to a $0.5 \mathrm{McF}$ arland standard. Antibiotic susceptibility testing was performed for both treated and control strains, by disk diffusion method, according to Clinical and Laboratory Standards Institute guidelines (CLSI 2016). The treated and untreated bacterial strains were tested for susceptibility to 12 antimicrobial agents: amoxicillin-clavulanic acid $(30 \mu \mathrm{g})$, penicillin (10 units), ampicillin $(10 \mu \mathrm{g})$, cefuroxime $(30 \mu \mathrm{g})$, ceftazidime $(30 \mu \mathrm{g})$, imipenem $(10 \mu \mathrm{g})$, gentamicin $(10 \mu \mathrm{g})$, tetracycline $(30 \mu \mathrm{g})$, nalidixic acid $(30 \mu \mathrm{g})$, vancomycin $(30 \mu \mathrm{g})$, erythromycin $(15 \mu \mathrm{g})$. All antibiotic disks were provided by Oxoid. Antimicrobial susceptibility/resistance profiles of the tested strains were established after measuring the diameter of the growth inhibition zone.

Table 3. Antibiotic panels used for different bacterial strains, according to CLSI 2016

\begin{tabular}{|c|c|}
\hline Antibiotics & Bacterial strains \\
\hline Amoxicillin-clavulanic acid (AMC) & \\
Cefuroxime (CXM) & \\
Ceftazidime (CAZ) & Enterobacteriaceae, \\
Imipenem (IMP) & Solther than \\
Gentamicin (CN) & \\
Tetracycline (TE) & \\
\hline Ampicillin (AMP) & Salmonella spp. \\
Nalidixic acid (NA) & \\
\hline Penicillin (P) & \\
Ampicillin (AMP) & \\
Tetracycline (TE) & Enterococcus spp. \\
Vancomycin (VA) & \\
Erythromycin (E) & \\
\hline
\end{tabular}




\section{Results and discussion}

The present study shows some preliminary results regarding the study of the influence of electromagnetic field on the antibiotic susceptibility of some bacterial strains isolated from wastewater (Table 1). The results demonstrate that the electromagnetic field exhibited a variable influence on the antibiotic susceptibility patterns of the tested strains.

The electromagnetic field induced a decrease of the growth inhibition diameters for penicillin, cephalosporins (ceftazidime, cefuroxime) and tetracycline. The most significant changes were noticed for the second and third generation cephalosporins cefuroxime and ceftazidime against Enterobacter sp., Citrobacter sp. and E. coli tested strains.

Table 4. Growth inhibition diameters and clinical category (susceptible, intermediate, resistant) before and after exposure to the electromagnetic field of Salmonella spp. and Enterococcus spp. strains

\begin{tabular}{|c|c|c|c|c|c|c|c|c|c|c|c|c|}
\hline \multirow{2}{*}{ Microbial strain } & \multicolumn{2}{|c|}{ NA } & \multicolumn{2}{|c|}{ AMP } & \multicolumn{2}{|c|}{$\mathbf{P}$} & \multicolumn{2}{|c|}{ VA } & \multicolumn{2}{|c|}{$\mathbf{E}$} & \multicolumn{2}{|c|}{ TE } \\
\hline & $1^{*}$ & $2^{* *}$ & $1^{*}$ & $2^{\star *}$ & $1^{*}$ & $2^{* \star}$ & $1^{*}$ & $2^{* \star}$ & $1^{*}$ & $2^{\star \star}$ & $1^{*}$ & $2^{* *}$ \\
\hline Salmonella arizonae & $\begin{array}{c}25 \\
S\end{array}$ & $\begin{array}{c}25 \\
S\end{array}$ & $\begin{array}{l}6 \\
R\end{array}$ & $\begin{array}{l}6 \\
R\end{array}$ & & & & & & & & \\
\hline Salmonella sp. & $\begin{array}{c}22 \\
S\end{array}$ & $\begin{array}{c}26 \\
S\end{array}$ & $\begin{array}{l}10 \\
\mathrm{R}\end{array}$ & $\begin{array}{c}10 \\
\mathrm{R}\end{array}$ & & & & & & & & \\
\hline Enterococcus sp. & & & $\begin{array}{l}15 \\
\mathrm{R}\end{array}$ & $\begin{array}{l}11 \\
\mathrm{R} \\
\end{array}$ & $\begin{array}{c}18 \\
\mathrm{~S}\end{array}$ & $\begin{array}{c}15 \\
S\end{array}$ & $\begin{array}{c}23 \\
S\end{array}$ & $\begin{array}{c}23 \\
S\end{array}$ & $\begin{array}{c}21 \\
1\end{array}$ & $\begin{array}{c}21 \\
1\end{array}$ & $\begin{array}{l}11 \\
\mathrm{R}\end{array}$ & $\begin{array}{l}8 \\
R\end{array}$ \\
\hline Enterococcus sp. & & & $\begin{array}{l}6 \\
\mathrm{R}\end{array}$ & $\begin{array}{l}6 \\
\mathrm{R}\end{array}$ & $\begin{array}{c}18 \\
\mathrm{~S}\end{array}$ & $\begin{array}{l}15 \\
S\end{array}$ & $\begin{array}{c}20 \\
\mathrm{~S}\end{array}$ & $\begin{array}{l}6 \\
\mathrm{R}\end{array}$ & $\begin{array}{c}16 \\
1\end{array}$ & $\begin{array}{c}14 \\
1\end{array}$ & $\begin{array}{c}17 \\
\text { I }\end{array}$ & $\begin{array}{c}15 \\
1\end{array}$ \\
\hline
\end{tabular}

Table 5. Growth inhibition diameters and clinical category (susceptible, intermediate, resistant) before and after exposure to the electromagnetic field of Enterobacteriaceae spp. strains

\begin{tabular}{|c|c|c|c|c|c|c|c|c|c|c|c|c|}
\hline \multirow{2}{*}{ Microbial strain } & \multicolumn{2}{|c|}{ AMC } & \multicolumn{2}{|c|}{ CXM } & \multicolumn{2}{c|}{ CAZ } & \multicolumn{2}{c|}{ IMP } & \multicolumn{3}{c|}{ CN } & \multicolumn{2}{c|}{ TE } \\
\cline { 2 - 13 } & $1^{*}$ & $2^{* *}$ & $1^{*}$ & $2^{* *}$ & $1^{*}$ & $2^{* *}$ & $1^{*}$ & $2^{* *}$ & $1^{*}$ & $2^{* *}$ & $1^{*}$ & $2^{* *}$ \\
\hline \multirow{2}{*}{ Enterobacter agglomerans } & 10 & 14 & 11 & 6 & 24 & 21 & 27 & 26 & 24 & 29 & 22 & 30 \\
& $\mathrm{R}$ & $\mathrm{I}$ & $\mathrm{R}$ & $\mathrm{R}$ & $\mathrm{S}$ & $\mathrm{S}$ & $\mathrm{S}$ & $\mathrm{S}$ & $\mathrm{S}$ & $\mathrm{S}$ & $\mathrm{S}$ & $\mathrm{S}$ \\
\hline \multirow{2}{*}{ Escherichia coli } & 15 & 17 & 16 & 13 & 18 & 15 & 30 & 33 & 27 & 30 & 23 & 19 \\
& $\mathrm{I}$ & $\mathrm{I}$ & $\mathrm{I}$ & $\mathrm{R}$ & $\mathrm{I}$ & $\mathrm{R}$ & $\mathrm{S}$ & $\mathrm{S}$ & $\mathrm{S}$ & $\mathrm{S}$ & $\mathrm{S}$ & $\mathrm{S}$ \\
\hline \multirow{2}{*}{ Citrobacter farmeri } & 16 & 16 & 18 & 13 & 30 & 21 & 23 & 24 & 16 & 15 & 15 & 18 \\
& $\mathrm{I}$ & $\mathrm{I}$ & $\mathrm{S}$ & $\mathrm{R}$ & $\mathrm{S}$ & $\mathrm{S}$ & $\mathrm{S}$ & $\mathrm{S}$ & $\mathrm{S}$ & $\mathrm{S}$ & $\mathrm{S}$ & $\mathrm{S}$ \\
\hline \multirow{2}{*}{ Klebsiella oxytoca } & 6 & 6 & 6 & 6 & 26 & 31 & 32 & 32 & 31 & 31 & 19 & 20 \\
& $\mathrm{R}$ & $\mathrm{R}$ & $\mathrm{R}$ & $\mathrm{R}$ & $\mathrm{S}$ & $\mathrm{S}$ & $\mathrm{S}$ & $\mathrm{S}$ & $\mathrm{S}$ & $\mathrm{S}$ & $\mathrm{S}$ & $\mathrm{S}$ \\
\hline \multirow{2}{*}{ Enterobacter sp. } & 19 & 17 & 14 & 13 & 29 & 15 & 21 & 17 & 21 & 12 & 21 & 18 \\
& $\mathrm{~S}$ & $\mathrm{I}$ & $\mathrm{R}$ & $\mathrm{R}$ & $\mathrm{S}$ & $\mathrm{R}$ & $\mathrm{I}$ & $\mathrm{R}$ & $\mathrm{S}$ & $\mathrm{R}$ & $\mathrm{S}$ & $\mathrm{S}$ \\
\hline \multirow{2}{*}{ Klebsiella sp. } & 34 & 26 & 18 & 18 & 6 & 6 & 40 & 36 & 34 & 31 & 31 & 31 \\
& $\mathrm{~S}$ & $\mathrm{~S}$ & $\mathrm{~S}$ & $\mathrm{~S}$ & $\mathrm{R}$ & $\mathrm{R}$ & $\mathrm{S}$ & $\mathrm{S}$ & $\mathrm{S}$ & $\mathrm{S}$ & $\mathrm{S}$ & $\mathrm{S}$ \\
\hline
\end{tabular}

* 1 = before (control sample - unexposed)

${ }^{* *} 2=$ after exposure to the electromagnetic field

In certain cases, the tested strains exhibited an increased resistance to the tested antibiotics, as revealed by the decrease of the growth inhibition diameters, 
comparatively to the unexposed strains (control sample). This was the case for the Gram-positive Enterococcus sp. strain for vancomycin, of Escherichia coli N61 for cefuroxime and ceftazidime, of Enterobacter sp. N60 for ceftazidime, gentamicin, AMC, imipenem (Fig. 1) and of Citrobacter farmeri O19 for cefuroxime (Fig. 2).

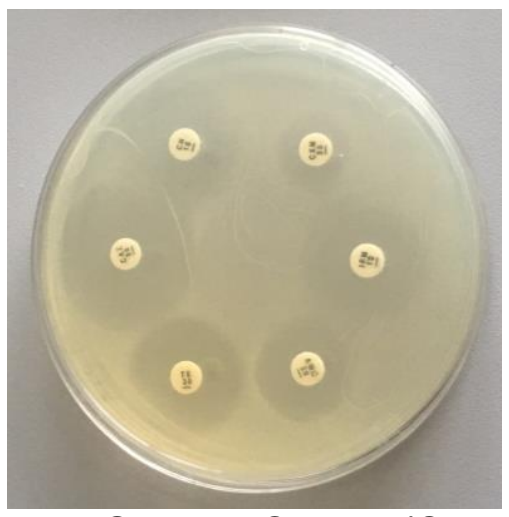
field)

Figure 1. Sample O19 M (Control)

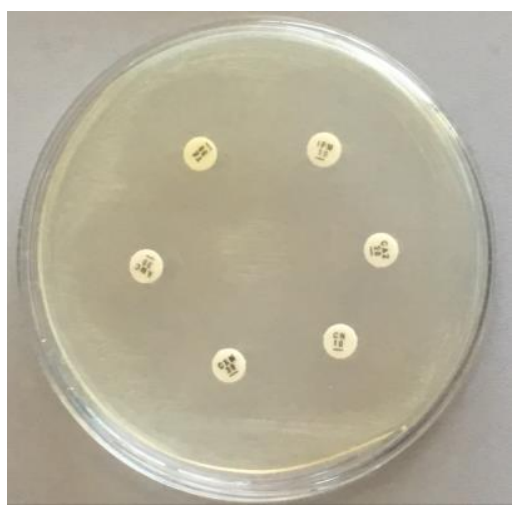

Figure 2. Sample N60 M (Control sample) However, in case of the Entero antibiotics exhibited slightly higher growth inhibition zone diameters (Fig. 3).

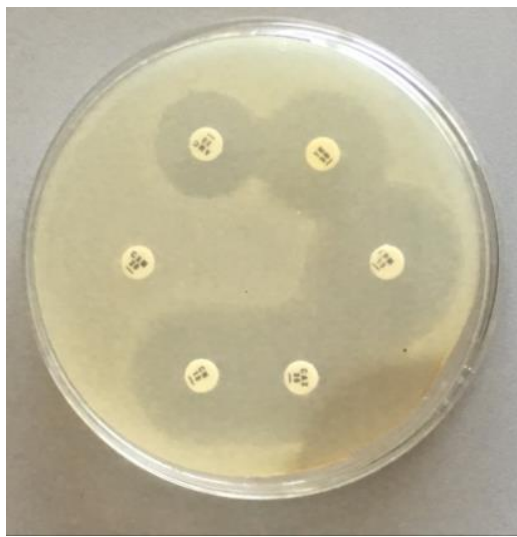

Figure 3. Sample N85 M (Control sample) ${ }^{\star} \mathrm{EM}=$ electromagnetic

\section{Conclusions}

The results regarding the antibiotic susceptibility of some bacterial strains isolated from wastewater and exposed to an electromagnetic field $50 \mathrm{~Hz}$ at different voltages showed

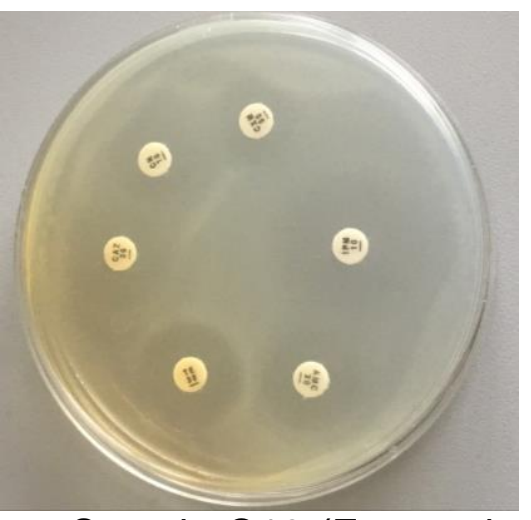

Sample 019 (Exposed to the EM*

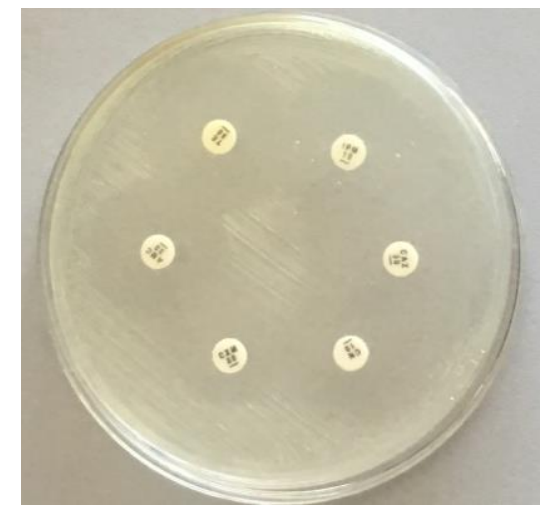

Sample N60 (Exposed to the EM* field) ter agglomerans N85 strain, all tested

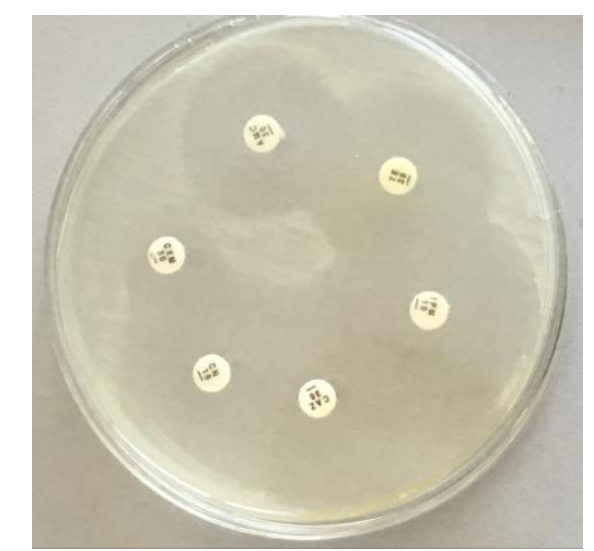

Sample N85 (Exposed to the EM* field) 
that certain bacterial strains exhibited a decreased susceptibility and even turned into resistant to antibiotics comparatively to the control samples (unexposed to an electromagnetic field), while others exhibited an increased susceptibility to some of the tested antibiotics. These preliminary results demonstrate that the electromagnetic filed in addition with other selective factors which are present in the wastewaters could modulate the environmental reservoir of antibiotic resistance and influence the frequency of the selection of resistant bacteria with a potential risk of dissemination into the environment and of contamination of animals and humans.

\section{Acknowledgements}

This work was financiary suported by National Project no. 161103 01/2016 and the research project PN-II-RU-TE- 2014-4-2037 from the Romanian National Authority of Scientific Research and Inovation.

\section{References}

1. Hirsch R., Ternes T., Haberer K., Kratz K.L., (1999), Occurrence of antibiotics in the aquatic environment, Science of the Total Environment, 225, 109-118.

2. Diaz-Cruz M.S., Lopez de Alda M.J., Barcelo D., (2003), Environmental behavior and analysis of veterinary and human drugs in soils, sediments and sludge, Trends in Analytical Chemistry, 22 (6), 340-351.

3. Brown K.D., Kulis J., Thomson B., Chapman T.H., Mawhinney D.B., (2006), Occurrence of antibiotics in hospital, residential, and dairy effluent, municipal wastewater and the Rio Grande in New Mexico, Science of the Total Environment, 366, 772-783.

4. Kummerer K., (2009), Antibiotics in the aquatic environment (a review), Part II. Chemosphere, 75, 435.

5. Czekalsk, N., Berthold T., Caucci S., Egli A., Burgmann H., (2012), Increased levels of multiresistant bacteria and resistance genes after wastewater treatment and their dissemination into Lake Geneva, Switzerland, Frontiers in Microbiology, 3 (106), 1-18.

6. Le Corre S.K., Ort C., Kateley D., Allen B., Escher B.I., Keller J., (2012) Consumptionbased approach for assessing the contribution of hospitals towards the load of pharmaceutical residues in municipal wastewater, Environment International, 45, 99-111.

7. Marcinek H., Wirth R., Muscholl-Silberhorn A., Gauer M., (1998), Enterococcus faecalis gene transfer under natural conditions in municipal sewage water treatment plants, Applied Environmental Microbiology, 64, 626-632.

8. Kim S., Jensen J.N., Aga S.D., Weber S.A., (2007), Tetracycline as a selector for resistant bacteria in activated sludge, Chemosphere, 66, 1643-1651.

9. Baquero F., Martinez J.L., Canton R., (2008), Antibiotics and antibiotic resistance in water environments, Current Opinion in Biotechnology, 19 (3), 260-265.

10. Martinez J.L., (2009), Environmental pollution by antibiotics and by antibiotic resistance determinants, Environmental Pollution, 157 (11), 2893-2902.

11. Skurnik D., Ruimy R., Ready D., Ruppe E., Berne`de-Bauduin C., Djossou F., Guillemot D., Pier G.B., Andremont A., (2010), Is exposure to mercury a driving force for the carriage of antibiotic resistance genes?, Journal of Medical Microbiology, 59 (7), 804-807.

12. Graham D.W., Olivares-Rieumont S., Knapp C.W., Lima L., Werner D., Bowen E., (2011), Antibiotic resistance gene abundances associated with waste discharges to the Almendares River near Havana, Cuba, Environmental Science\&Technology 45 (2), 418-424.

13. Espigares E., Bueno A., Espigares M., Galvez R., (2006), Isolation of Salmonella serotypes in wastewater and effluent: effect of treatment and potential risk, International Journal Hygiene Environmental Health, 209,103-107.

14. Hawkey P.M., (2008), Molecular epidemiology of clinically significant antibiotic resistance genes, British Journal Pharmacology, 153, S406-S413. 
15. Thiele-Bruhn S., Beck I.C., (2005), Effects of sulfonamide and tetracycline antibiotics on soil microbial activity and microbial biomass, Chemosphere, 59, 457-465.

16. Martinez J.L., (2009), Environmental pollution by antibiotics and by antibiotic resistance determinants, Environmental Pollution, 157, 2893-2902.

17. Bouki C., Venieri D., Diamadopoulos E., (2013), Detection and fate of antibiotic resistant bacteria in wastewater treatment plants: A review, Ecotoxicology and Environmental Safety, 91, 1-9.

18. Alekshun M.N., Levy S.B., (2007), Molecular mechanisms of antibacterial multi drug resistance, Cell, 128, 1037-1050.

19. Aminov R.I, (2011), Horizontal gene exchange in environmental microbiota, Frontiere in Microbiology, 2, 158.

20. Cho C.W., Pham T.P., Jeon Y.C., Vijayaraghavan K., Choe W.S., Yun Y.S., (2007), Toxicity of imidazolium salt with an ion bromide to a phytoplankton Selenastrum capricornutum: effectofalkyl-chainlength, Chemosphere, 69, 1003-1007.

21. DeBruyn J.M., Mead T.J., Sayler G.S., (2011), Horizontal transfer of PAH catabolism gene sinMycobacterium: evidence from comparative genomics and isolatedpyrene-degrading bacteria, Environmental Science Technology, 46, 99-106.

22. Jones O.A.H., Voulvoulis, N., Lester, J.N., (2001), Human pharmaceuticals in the aquatic environment a review, Environmental Science and Technology, 22, 1383-1394.

23. Heberer T., (2002) Occurrence, fate, and removal of pharmaceutical residues in the aquatic environment: a review of recent research data, Toxicology Letters, 131, 5-17.

24. Batt A.L., Kim S., Aga D.S., (2007), Comparison of the occurrence of antibiotics in four full-scale wastewater treatment plants with varying designs and operations, Chemosphere, 68, 428-435.

25. Fatta-Kassinos D., Vasquez M.I., Kummerer K., (2011b), Transformation products of pharmaceuticals in surface waters and wastewater formed during photolysis and advanced oxidation processes e degradation, elucidation of byproducts and assessment of their biological potency, Chemosphere, 85, 693-709.

26. Boxall A.B.A., (2004), The environmental side effects of medication, EMBO, 5, 1110-1116.

27. Hingst V., Klippel K.M., Sonntag H., (1995), Epidemiology of microbial resistance to biocides, Zentralbl. Hyg. Umweltmed., 197, 232-251.

28. Russel A.D., (2000), Do biocides select for antibiotic resistance?, Journal Pharmacology, 52, 227-233.

29. Zhang T., Zhang M., Zhang X., Fang H.H., (2009a), Tetracycline resistance genes and tetracycline resistant lactose-fermenting Enterobacteriaceae in activated sludge of sewage treatment plants, Environmental Science Technology, 43, 3455-3460.

30. Zhang Y., Marrs C.F., Simon C., Xi C., (2009b), Wastewater treatment contributes to selective increase of antibiotic resistance among Acinetobacter spp., Science Total Environmental, 407, 3702-3706.

31. Auerbach E.A., Seyfried E.E., McMahon K.D., (2007), Tetracycline resistance genes in activated sludge wastewater treatment plants, Water Research, 41, 1143-1151.

32. Brooks J.P., Maxwell S.L., Rensing C., Gerba C.P., Pepper I.L., (2007), Occurrence of antibiotic-resistant bacteria and endotoxin associated with the land applica- tion of biosolids, Canadian Journal Microbiology, 53, 616-622.

33. Hunt R. W., Zavalin A., Bhatnagar A., Chinnasamy S., Das K. C., (2009), Electromagnetic Biostimulation of Living Cultures for Biotechnology, Biofuel and Bioenergy Applications, International Journal Molecular Science, 10, 4515-4558.

34. Marino A., Becker R.O., (1977), Biological effects of extremely low frequency Electric and magnetic fields: a review, Physiology Chemical \& Physics, 9, 131-142.

35. Stoica M., Bahrim G., Cârâc G., (2011), Factors that Influence the Electric Field Effects on Fungal Cells, Science against microbial pathogens: communicating current research and technological advances, 291-302. 